\title{
A Novel Calcium-Dependent Protein Kinase 1 Inhibitor Potently Prevents Toxoplasma gondii Transmission to Foetuses in Mouse
}

\author{
Héloïse Débare ${ }^{1, t} \neq \pm\left(\mathbb{D}\right.$, Nathalie Moiré ${ }^{1, \ddagger}$, Firmin Baron ${ }^{1} \mathbb{D}$, Louis Lantier ${ }^{1}\left(\mathbb{D}\right.$, Bruno Héraut ${ }^{1}$, \\ Nathalie Van Langendonck ${ }^{2}$, Caroline Denevault-Sabourin ${ }^{3}$, Isabelle Dimier-Poisson ${ }^{1}$ \\ and Françoise Debierre-Grockiego ${ }^{1, *(D)}$
}

check for updates

Citation: Débare, H.; Moiré, N.; Baron, F.; Lantier, L.; Héraut, B.; Van Langendonck, N.; Denevault-Sabourin, C.; Dimier-Poisson, I.;

Debierre-Grockiego, F. A Novel Calcium-Dependent Protein Kinase 1 Inhibitor Potently Prevents Toxoplasma gondii Transmission to Foetuses in Mouse. Molecules 2021, 26, 4203. https://doi.org/10.3390/ molecules26144203

Academic Editor: Pascal Marchand

Received: 15 June 2021

Accepted: 7 July 2021

Published: 10 July 2021

Publisher's Note: MDPI stays neutral with regard to jurisdictional claims in published maps and institutional affiliations.

Copyright: (c) 2021 by the authors. Licensee MDPI, Basel, Switzerland. This article is an open access article distributed under the terms and conditions of the Creative Commons Attribution (CC BY) license (https:/ / creativecommons.org/licenses/by/ $4.0 /)$.
1 Infectiologie et Santé Publique, National Research Institute for Agriculture, Food and the Environment, Université de Tours, 37000 Tours, France; heloise.debare@gmail.com (H.D.); nathalie.moire@univ-tours.fr (N.M.); firmin.baronc2i@gmail.com (F.B.); louis.lantier@univ-tours.fr (L.L.); bruno.heraut@univ-tours.fr (B.H.); dimier@univ-tours.fr (I.D.-P.)

2 Service de Parasitologie-Mycologie-Médecine Tropicale, Centre Hospitalier Régional Universitaire de Tours, 37000 Tours, France; langendo@univ-tours.fr

3 Groupe Innovation et Ciblage Cellulaire EA7501, Université de Tours, 37200 Tours, France; caroline.denevault@univ-tours.fr

* Correspondence: francoise.debierre@univ-tours.fr; Tel.: +33-247-366-983

+ Present address: Animal Genetics and Innovative Biology, National Research Institute for Agriculture, Food and the Environment, 78352 Jouy-en-Josas, France.

$\ddagger$ These authors contributed equally to this work.

Abstract: Treatments currently used to prevent congenital toxoplasmosis are non-specific of Toxoplasma gondii and have grievous side effects. To develop a more specific and less toxic drug, we have designed SP230, an imidazo[1,2-b]pyridazine salt targeting the Toxoplasma gondii calcium-dependent protein kinase 1 ( $\mathrm{TgCDPK} 1$ ) and active against acute toxoplasmosis in mice. Efficiency of SP230 to inhibit foetal transmission of the parasite was evaluated in a mouse model of congenital toxoplasmosis. Swiss mice were infected at mid-pregnancy with tachyzoites or cysts of the ME49 strain of T. gondii by intraperitoneal and oral route, respectively, and treated with SP230 at $50 \mathrm{mg} / \mathrm{kg}$ for 5 days by the same routes. Parasite burden in organs of dams and in foetuses was measured by quantitative PCR. Intraperitoneal administration of SP230 drastically reduced the number of parasites (more than 97\% of reduction) in the brain and lungs of dams, and led to a reduction of $66 \%$ of parasite burden in foetuses. Oral administration of SP230 was particularly efficient with $97 \%$ of reduction of parasite burdens in foetuses. SP230 did not impact number and weight of offspring in our conditions. This inhibitor of $T g C D P K 1$ is a promising candidate for the development of alternative therapeutics to treat infected pregnant women.

Keywords: Toxoplasma gondii; congenital toxoplasmosis; treatment; imidazoazines

\section{Introduction}

Human beings are at risk of infection with the apicomplexan parasite Toxoplasma gondii mainly by ingestion of cysts present in undercooked meat. After ingestion, bradyzoites are liberated from cysts and differentiate into tachyzoites, the parasite form replicating within the host cells. In pregnant women, tachyzoites can cross the placental barrier and infect the foetus resulting in congenital toxoplasmosis. The probability of foetal infection and the severity of further complications depend on the gestational age at the time of infection. During the first trimester, the trans-placental passage is less likely, but in case of foetus contamination, the damages are often severe, characterized by the classical triad of chorioretinitis, intracranial calcifications or hydrocephalus [1]. As pregnancy progresses, the rate of vertical transmission proportionally increases, resulting in the second trimester, 
in preterm births and/or neurologic and ocular disorders in new-born babies. Finally, during the third trimester, the foetal infection is of high risk but generally subclinical, with latent forms, sometimes leading to delayed neurological or ophthalmological sequelae [2]. The macrolide antibiotic spiramycin is often used to inhibit transmission of infection to the foetus but is inefficient when foetal contamination is confirmed, because it cannot cross the placental barrier [3]. At this stage, the therapeutic option widely used is an association of pyrimethamine with a sulphonamide drug, targeting the T. gondii folate pathway, characterized by a modest efficacy, long periods of treatment and significant side effects $[4,5]$. Novel treatment options are thus required.

A large number of anti-Toxoplasma compounds has been described in the literature, but very few studies on drug efficacy in a congenital model are available [6]. We have previously demonstrated the outstanding efficacy of the imidazo[1,2-b]pyridazine salt SP230, a T. gondii calcium-dependent protein kinase 1 (TgCDPK1) inhibitor that strongly reduced parasite burdens in the brain and lungs of non-pregnant infected mice [7]. In addition, we have shown that SP230 exhibited excellent systemic exposure, with a high blood-brain barrier penetration in mice when administered by intraperitoneal route [7].

We here report on the safety and efficacy of SP230 against vertical transmission of T. gondii. Like humans, mice are natural intermediate hosts of $T$. gondii and because of the high number of offspring per litter, robust statistical analyses are possible with only few pregnant Swiss females. Mice were infected at mid-pregnancy, the optimal time for foetal transmission without abortion. In our previous study, SP230 was administered by intraperitoneal route to mice infected by the same route. Since natural infection and treatment of pregnant women occur by oral route, we here compared both routes of infection/treatment.

\section{Results}

\subsection{Chemical Synthesis of SP230 and Validation of Its Therapeutic Index}

The batch of SP230 synthesized for this study had similar therapeutic index than in our previous work [7], with a $\mathrm{CE}_{50}$ of $0.080 \mu \mathrm{M}$ on $\mathrm{T}$. gondii tachyzoites in vitro and a $\mathrm{CC}_{50}$ of more than $30 \mu \mathrm{M}$ on the human foreskin fibroblasts used as host cells for tachyzoite growth in vitro $\left(\mathrm{CC}_{50} / \mathrm{CE}_{50}>350\right)$.

\subsection{Establishment of Specific Standard Curves for $q P C R$}

To evaluate the efficiency of $T$. gondii inhibitors, the qPCR method is often used to detect the parasites in organs of treated animals and a standard curve obtained with known amount of tachyzoites is used to precisely quantify them $[8,9]$. Since T. gondii DNA is extracted together with organ DNA, we wanted to decipher whether this host DNA interferes with the amplification of the parasite DNA. For this, we performed four different standard curves with known amounts of tachyzoites alone or added to brain, lungs or foetus from non-infected mice. By this way, we found out that the crossing point (minimum number of cycles required to detect amplified DNA) was different according to the type of tissue (i.e., of crossing points for 1000 tachyzoites: 23.6 in brain, 21.2 in lungs, 23.8 in foetus and 22.9 for tachyzoites alone). Processing of DNA of non-infected tissue gave no crossing point value. In light of these results, parasite burdens in infected mice were calculated with the appropriate standard curve.

\subsection{SP230-Treatment of Pregnant Mice Infected with T. gondii}

To evaluate the efficiency of SP230 to inhibit the transmission of T. gondii to foetus, mice were infected at mid-gestation either with tachyzoites by intraperitoneal route or orally with cysts and treated with SP230 administered by the same route than infection. After 17 days of gestation, parasite burden was quantified by qPCR in brain and lungs of dams and in foetuses. As shown in Figure 1a, both intraperitoneal and oral treatments of pregnant mice with SP230 significantly reduced parasite burdens in brain of dams with global reduction of $98 \%(p<0.01)$ and $96 \%(p<0.05)$, respectively. The decrease in 
parasite numbers observed in lungs of dams was significant $(p<0.05)$ after intraperitoneal treatment $(97 \%)$, but not after oral treatment $(49 \%)$. This might be explained by the 23 -fold lower number of parasites in the lungs of untreated mice infected orally compared to those infected by the intraperitoneal route (Figure 1b). In contrast to these results on dams, the inhibition of vertical transmission of $T$. gondii was more efficient after oral treatment (Figure 1c). Indeed, the reduction in parasite burdens in foetuses reached $97 \%$ when dams were orally treated with SP230 $(p<0.0001)$, while the diminution was of $66 \%$ in the case of intraperitoneal administration $(p<0.05)$. Contrary to the dams, the number of parasites in foetuses was more elevated when mice were infected orally, and the significance of the difference with the treated group was consequently more stringent.

(a)

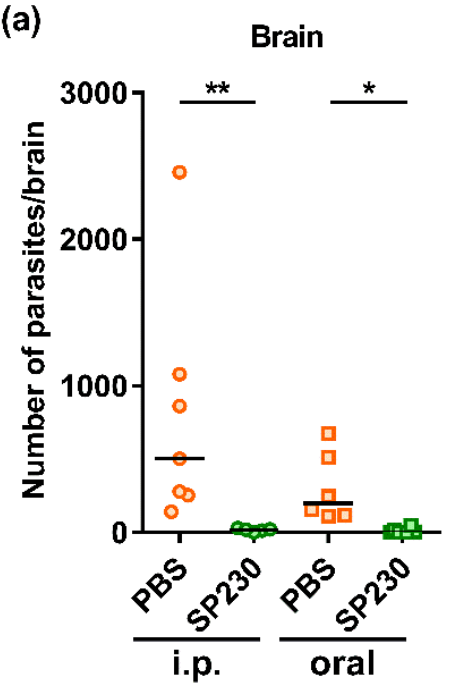

(b)

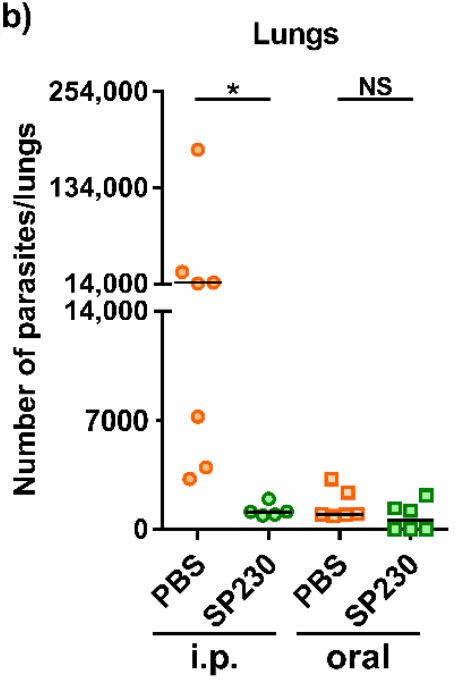

(c)
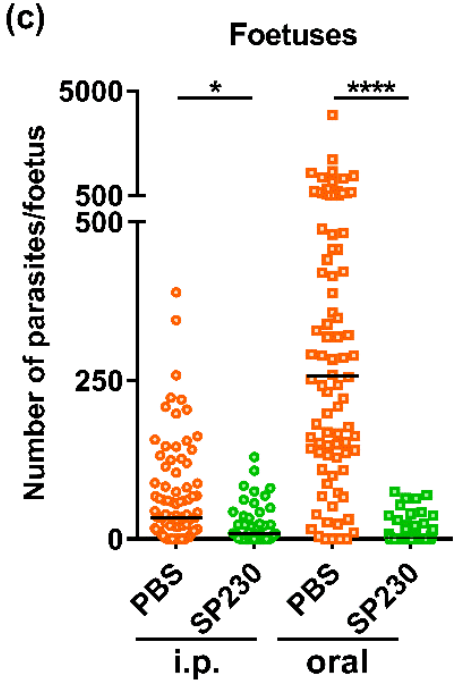

Figure 1. Mice were infected at mid-gestation by tachyzoites (intraperitoneal route, i.p.) or cysts (oral route) of the ME49 strain of T. gondii. Mice received PBS or SP230 $(50 \mathrm{mg} / \mathrm{kg})$ by the same routes for 5 days. The number of T. gondii parasites was evaluated by qPCR at day 17 of gestation in brain (a) and lungs (b) of dams ( $n=5$ to 7$)$ or in foetuses ((c), $n=90$ [PBS i.p., 5 dams], 47 [SP230 i.p., 3 dams], 86 [PBS oral, 6 dams] and 53 [SP230 oral, 3 dams]). NS: not significant, ${ }^{*} p<0.05$, ${ }^{* *} p<0.01,{ }^{* * * *} p<0.0001$ (Dunn's multiple comparison test).

\subsection{SP230-Treatment of Pregnant Non-Infected Mice}

In the experiment described in the (Section 2.3), the number of foetuses was not significantly different after SP230 treatment of T. gondii-infected mice compared to the control groups (PBS i.p.: $18 \pm 3$ and SP230 i.p.: $16 \pm 2$, $p$ value $=0.439$; PBS p.o.: $14 \pm 1$ and SP230 p.o.: $18 \pm 1, p$ value $=0.0838$, Dunn's multiple comparisons test after KruskalWallis test). To firmly exclude a toxic effect of SP230 during pregnancy, non-infected mice were treated following the same schedule as for the previous experiment. The number of offspring was slightly higher in the group of animals that received PBS per oral route, but the difference with the SP230 group was not significant (Table 1). The number of offspring was very similar when mice received PBS or SP230 by the intraperitoneal route. At 4 weeks, the mean weight of female and male offspring born from mice treated with SP230 by the intraperitoneal route was higher than those of female and male offspring born from control mice (PBS i.p.). No significant difference in weight was observed between the two groups from animals orally treated (Table 1).

In conclusion, oral administration of imidazoazine SP230 provided strong protection against foetal infection by T. gondii in mouse without negative effect on the progeny in terms of offspring number and growth in the present therapeutic protocol. 
Table 1. Number and weight of offspring. CBA/J mice received PBS or $50 \mathrm{mg} / \mathrm{kg}$ of SP230 by intraperitoneal (i.p.) or oral route for 5 days during gestation. Weight of offspring was recorded at the age of 4 weeks. Results are expressed as mean \pm standard deviation. Statistical differences were calculated with the Dunn's multiple comparison test between the PBS i.p. and SP230 i.p. groups and between the PBS oral and SP230 oral groups ( ${ }^{\text {ns }}$ not significant; ${ }^{\mathrm{a}} p$ value $=0.0437{ }^{\mathrm{b}} p$ value $=0.0236$ ).

\begin{tabular}{cccc}
\hline Treatment of Dams & Number of Offspring & Weight of Female & Weight of Male \\
\hline PBS i.p. $(n=9)$ & $4 \pm 2$ & $17.4 \pm 1.6$ & $19.6 \pm 1.2$ \\
SP230 i.p. $(n=9)$ & $3.89 \pm 1^{\text {ns }}$ & $18.6 \pm 2.3^{\mathrm{a}}$ & $21.6 \pm 2.4^{\mathrm{b}}$ \\
PBS oral $(n=9)$ & $5.22 \pm 2$ & $17.4 \pm 2.4$ & $20.5 \pm 1.5^{\mathrm{ns}}$ \\
SP230 oral $(n=9)$ & $4.11 \pm 2^{\mathrm{ns}}$ & $16.7 \pm 2.8^{\mathrm{ns}}$ & $21.9 \pm 2.3^{\mathrm{ns}}$ \\
\hline
\end{tabular}

\section{Discussion}

Toxoplasmosis is the first parasitic foodborne disease responsible for high healthcare costs. For few years, guidelines for prevention, diagnosis and treatment of congenital toxoplasmosis have been published by working groups from different countries to prevent complications [3,10-13]. In France and Austria, systematic serological screening of antiToxoplasma antibodies in pregnant women permits for starting the treatment very early after infection. On the contrary, the cost of diagnosis is estimated to be too high in the USA to be generalized to all pregnant women, leading to an underestimation of the number of cases $[11,14,15]$. As a consequence of these different public health policies, the rate of severe clinical signs like hydrocephaly is much higher in the USA than in France in infants congenitally infected with the same type of T. gondii strain [16-18]. A retrospective analysis of 11 studies has estimated the rate of vertical transmission at $9.9 \%$ after therapy [4], indicating that it is not optimal. This could be due to inefficacy of the first line treatments on sulfadiazine-resistant strains [19]. Furthermore, hematologic disorders like neutropenia (1.7 to $45.8 \%$ ), anaemia ( 0.8 to $50 \%$ ), thrombocytopenia (6.9 to $7.7 \%$ ) and eosinophilia (26.2\%) are often observed in patients with maternal and congenital toxoplasmosis treated with pyrimethamine [20], highlighting the importance of developing alternative therapeutics more specific without undesirable side effects.

Among TgCDPK1 inhibitors, the bumped kinase inhibitor BKI-1294 demonstrated excellent efficiency against trans-placental transmission of $T$. gondii in pregnant mice (reduction $>90 \%$ ) but with potential detrimental effect on fertility [8]. When BKI-1294 was administered to ewes from mid-gestation, no abortion and no loss of weight was observed at birth of lambs [21]. In our present study, there were 12 to 19 and 14 to 19 offspring per litter in control (PBS) and SP230-treated groups, respectively, suggesting that our T. gondii inhibitor does not affect mouse gestation at the tested dose. This was confirmed by the treatment of non-infected mice. In addition, administration of SP230 for 8 days did not trigger significant toxicity in liver and kidney of mice [7], but its administration to other animal species will be nonetheless necessary to conclude to its innocuousness during pregnancy before any use in human. It is noteworthy that SP230, administered by the intra-peritoneal route, drastically reduced the parasite load in brain and lungs as efficiently in pregnant mice (the present study) as in non-pregnant mice [7], suggesting that gestation does not impact the bio-distribution of SP230.

When ewes were infected with T. gondii at mid-gestation, the treatment with BKI-1294 increased survival of lambs (from 0 without treatment to 76\%), but DNA of T. gondii was detected in the brain of $46 \%$ of the lambs born alive [21]. BKI-1294 is thus not totally efficient in inhibiting vertical transmission of T. gondii in ewes. In our conditions, parasite DNA was not detected in all foetuses either in treated or untreated mice infected with T. gondii tachyzoites or cysts. The percentages of foetuses negative for infection increased from $21 \%$ and $5 \%$ (for mice that have received PBS by i.p. route and oral route, respectively) to $40 \%$ and $62 \%$ (for mice that have received SP 230 by i.p. route and oral route, respectively). In addition, T. gondii-positive foetuses from SP230-treated mice presented lower parasite loads than T. gondii-positive foetuses of the untreated groups. 
Although the protective effect of SP230 against congenital toxoplasmosis should be confirmed on offspring (significant increased survival, decreased ocular damages and parasite load), these results are encouraging for the development of a new treatment of congenital toxoplasmosis.

\section{Materials and Methods}

\subsection{Chemical Synthesis of SP230}

The compound 2-(benzo[d][1,3]dioxol-4-yl)-6-(4-methylpiperazin-1-yl)-3-(pyridin-4yl)imidazo[1,2-b]pyridazine bis hydrochloride salt (SP230) was synthesized by McSAF (Tours, France) according to Moine et al. [7].

\subsection{Functional Characterization of SP230}

Inhibitory activity of SP230 on the invasion/proliferation of T. gondii tachyzoites of the T. gondii RH- $\beta$-gal strain and absence of cytotoxicity on human foreskin fibroblasts were verified in vitro as previously described [7].

\subsection{Treatment of T. gondii-Infected Mice with SP230}

The number of animals required to have significant differences in the parasite loads was calculated with tools of Anastats.fr (AnaStats Scop ARL, Rilly-sur-Vienne, France). Twenty-four female Swiss mice of 20-30 g were purchased from Janvier Labs (Le GenestSaint-Isle, France) and maintained in the animal house of the University of Tours at 3 per cage and supplied with water and food ad libitum. The experimental protocol, carried out in accordance with the European Union Directive (2010/63/EU), was approved by the Ethics Committee $\mathrm{n}^{\circ} 019$ and the French Ministry for Research (permit number APAFIS\#6622-2016090215037378 v5). After mating, pregnancy was estimated by gain of weight. Between day 8 and 10 of gestation, 2 groups of mice $(n=7$ for the group 1 and $n=5$ for the group 2) received by intraperitoneal route 1000 tachyzoites of the T. gondii ME49 type 2 strain (Toxoplasma Biological Resource Centre, Reims, France) and 2 groups of mice ( $n=6$ for groups 3 and 4) received by oral route 10 cysts of the ME49 strain obtained from the brain of one CBA/J (Janvier Labs) chronically infected mouse (permit number 01915.03). Groups 1 and 3 received $200 \mu \mathrm{L}$ of PBS for 5 days by intraperitoneal route and oral route, respectively. Groups 2 and 4 received $200 \mu \mathrm{L}$ of SP230 at $50 \mathrm{mg} / \mathrm{kg}$ for 5 days by intraperitoneal route and oral route, respectively. Mice were euthanized by cervical dislocation at day 17 of gestation. Foetuses were immediately delivered by transabdominal incision and euthanized by decapitation.

\subsection{Quantitation of Parasite Loads by qPCR}

DNA of brain and lungs from dams and DNA of foetuses were extracted as described [7]. Quantitative PCR (qPCR) was performed on $250 \mathrm{ng}$ of genomic DNA in a total volume of $20 \mu \mathrm{L}$ containing LightCycler ${ }^{\circledR}$ Taqman $^{\circledR}$ Master mix (Roche Diagnostics, Meylan, France), $0.5 \mu \mathrm{M}$ of the 2 primers TG IIII $5^{\prime}$-CCT TGG CCG ATA GGT CTA GG-3'; TG IIb: $5^{\prime}$-GGC ATT CCT CGT TGA AGA TT- $3^{\prime}$, and $180 \mathrm{nM}$ of the probe $5^{\prime}$-FAM-TGC AAT AAT CTA TCC CCA TCA CGA TGC ATA CTC AC-TAMRA-3' (Eurofins Genomics, Ebersberg, Germany). The qPCR program was $2 \mathrm{~min}$ at $50{ }^{\circ} \mathrm{C}, 5 \mathrm{~min}$ at $95{ }^{\circ} \mathrm{C}, 50$ cycles of $20 \mathrm{~s}$ at $95^{\circ} \mathrm{C} / 60 \mathrm{~s}$ at $65^{\circ} \mathrm{C}$ with the LightCycler ${ }^{\circledR} 2.0$ Instrument (Roche Diagnostics). Standard curves were generated by extracting DNA of known amounts of tachyzoites alone or with the DNA of brain, lungs or foetus of non-infected mice. The non-parametric Kruskal-Wallis followed by the Dunn's multiple comparison post-test was used for statistical evaluation (GraphPad Prism 7 software, San Diego, CA, USA).

\subsection{Survival of Offspring Born from Mice Treated with SP230}

Twenty-six female CBA/J of 20-30 g were purchased from Janvier Labs (France) and maintained in the animal house of the University of Tours at 3 per cage and supplied with water and food ad libitum. The experimental protocol, carried out in accordance with the 
European Union Directive (2010/63/EU), was approved by the Ethics Committee ${ }^{\circ} 019$ and the French Ministry for Research (permit number APAFIS\#28673-2020121513492800 v4). Between day 8 and 10 of gestation, 2 groups of 9 mice received $200 \mu \mathrm{L}$ of PBS for 5 days by intraperitoneal route and oral route, respectively and 2 groups of 9 mice received $200 \mu \mathrm{L}$ of SP230 at $50 \mathrm{mg} / \mathrm{kg}$ for 5 days by intraperitoneal route and oral route, respectively. Survival and weight were recorded at 4 weeks of age.

Author Contributions: Conceptualization, C.D.-S., I.D.-P. and F.D.-G.; methodology, N.M., C.D.-S., I.D.-P. and F.D.-G.; investigation, H.D., N.M., F.B., L.L., B.H., N.V.L., I.D.-P. and F.D.-G.; writingoriginal draft, C.D.-S. and F.D.-G.; funding acquisition, I.D.-P. and F.D.-G. All authors have read and agreed to the published version of the manuscript.

Funding: This research was funded by the British Society for Antimicrobial Chemotherapy (grant number GA2016_020P to F.D.G), the Universite de Tours (annual endowment to I.D.P. and F.D.G.), and by the Région Centre-Val de Loire (PhD fellowship to H.D.).

Institutional Review Board Statement: The study was conducted according to the guidelines of the Declaration of Helsinki, and approved by the Ethics Committee Val de Loire (n $\left.{ }^{\circ} 019\right)$. It was authorized by the French Ministry for Research (permit numbers 01915.03-date of approval 12 May 2017; APAFIS\#6622-2016090215037378 v5-date of approval 31 March 2017; APAFIS\#28673$2020121513492800 \mathrm{v} 4$ - date of approval 28 January 2021).

Informed Consent Statement: Not applicable.

Data Availability Statement: The data presented in this study are available on request from the corresponding author.

Conflicts of Interest: The funders had no role in the design of the study; in the collection, analyses, or interpretation of data; in the writing of the manuscript, or in the decision to publish the results. F.D.G. was invited to present part of these results at the Antibiotic Resistance Mechanisms Meeting for BSAC grant holders held on December 2017 in Birmingham, UK. All other authors: none to declare.

Sample Availability: Samples of the congenital experiment (DNA) are available from the authors.

\section{References}

1. Khan, K.; Khan, W. Congenital toxoplasmosis: An overview of the neurological and ocular manifestations. Parasitol. Int. 2018, 67, 715-721. [CrossRef]

2. Picone, O.; Fuchs, F.; Benoist, G.; Binquet, C.; Kieffer, F.; Wallon, M.; Wehbe, K.; Mandelbrot, L.; Villena, I. Toxoplasmosis screening during pregnancy in France: Opinion of an expert panel for the CNGOF. J. Gynecol. Obstet. Hum. Reprod. 2020, $49,101814$. [CrossRef]

3. Peyron, F.; L'ollivier, C.; Mandelbrot, L.; Wallon, M.; Piarroux, R.; Kieffer, F.; Hadjadj, E.; Paris, L.; Garcia-Meric, P. Maternal and Congenital Toxoplasmosis: Diagnosis and Treatment Recommendations of a French Multidisciplinary Working Group. Pathogens 2019, 8, 24. [CrossRef]

4. Wei, H.-X.; Wei, S.-S.; Lindsay, D.S.; Peng, H.-J. A Systematic Review and Meta-Analysis of the Efficacy of Anti-Toxoplasma gondii Medicines in Humans. PLoS ONE 2015, 10, e0138204. [CrossRef]

5. Teil, J.; Dupont, D.; Charpiat, B.; Corvaisier, S.; Vial, T.; Leboucher, G.; Wallon, M.; Peyron, F. Treatment of Congenital Toxoplasmosis: Safety of the Sulfadoxine-Pyrimethamine Combination in Children Based on a Method of Causality Assessment. Pediatr. Infect. Dis. J. 2016, 35, 634-638. [CrossRef]

6. Montazeri, M.; Mehrzadi, S.; Sharif, M.; Sarvi, S.; Shahdin, S.; Daryani, A. Activities of anti-Toxoplasma drugs and compounds against tissue cysts in the last three decades (1987 to 2017), a systematic review. Parasitol. Res. 2018, 117, 3045-3057. [CrossRef]

7. Moine, E.; Moiré, N.; Dimier-Poisson, I.; Brunet, K.; Couet, W.; Colas, C.; Van Langendonck, N.; Enguehard-Gueiffier, C.; Gueiffier, A.; Héraut, B.; et al. Imidazo[1,2-b]pyridazines targeting Toxoplasma gondii calcium-dependent protein kinase 1 decrease the parasite burden in mice with acute toxoplasmosis. Int. J. Parasitol. 2018, 48, 561-568. [CrossRef]

8. Müller, J.; Aguado-Martínez, A.; Ortega-Mora, L.-M.; Moreno-Gonzalo, J.; Ferre, I.; Hulverson, M.A.; Choi, R.; McCloskey, M.C.; Barrett, L.K.; Maly, D.J.; et al. Development of a murine vertical transmission model for Toxoplasma gondii oocyst infection and studies on the efficacy of bumped kinase inhibitor (BKI)-1294 and the naphthoquinone buparvaquone against congenital toxoplasmosis. J. Antimicrob. Chemother. 2017, 72, 2334-2341. [CrossRef]

9. Hulverson, M.A.; Bruzual, I.; McConnell, E.V.; Huang, W.; Vidadala, R.S.R.; Choi, R.; Arnold, S.L.M.; Whitman, G.R.; McCloskey, M.C.; Barrett, L.K.; et al. Pharmacokinetics and In Vivo Efficacy of Pyrazolopyrimidine, Pyrrolopyrimidine, and 5-Aminopyrazole4-Carboxamide Bumped Kinase Inhibitors against Toxoplasmosis. J. Infect. Dis. 2019, 219, 1464-1473. [CrossRef] 
10. Paquet, C.; Yudin, M.H. Society of Obstetricians and Gynaecologists of Canada Toxoplasmosis in pregnancy: Prevention, screening, and treatment. J. Obstet. Gynaecol. Can. 2013, 35, 78-81. [CrossRef]

11. Maldonado, Y.A.; Read, J.S. COMMITTEE ON INFECTIOUS DISEASES Diagnosis, Treatment, and Prevention of Congenital Toxoplasmosis in the United States. Pediatrics 2017, 139. [CrossRef] [PubMed]

12. El Bissati, K.; Levigne, P.; Lykins, J.; Adlaoui, E.B.; Barkat, A.; Berraho, A.; Laboudi, M.; El Mansouri, B.; Ibrahimi, A.; Rhajaoui, M.; et al. Global initiative for congenital toxoplasmosis: An observational and international comparative clinical analysis. Emerg. Microbes. Infect. 2018, 7, 165. [CrossRef]

13. Montoya, J.G. Systematic screening and treatment of toxoplasmosis during pregnancy: Is the glass half full or half empty? Am. J. Obstet. Gynecol. 2018, 219, 315-319. [CrossRef] [PubMed]

14. Belk, K.; Connolly, M.P.; Schlesinger, L.; Ben-Harari, R.R. Patient and treatment pathways for toxoplasmosis in the United States: Data analysis of the Vizient Health Systems Data from 2011 to 2017. Pathog. Glob. Health 2018, 112, 428-437. [CrossRef] [PubMed]

15. Ben-Harari, R.R.; Connolly, M.P. High burden and low awareness of toxoplasmosis in the United States. Postgrad. Med. 2019, 131, 103-108. [CrossRef]

16. Wallon, M.; Peyron, F. Effect of Antenatal Treatment on the Severity of Congenital Toxoplasmosis. Clin. Infect. Dis. 2016, 62, 811-812. [CrossRef]

17. Peyron, F.; Mc Leod, R.; Ajzenberg, D.; Contopoulos-Ioannidis, D.; Kieffer, F.; Mandelbrot, L.; Sibley, L.D.; Pelloux, H.; Villena, I.; Wallon, M.; et al. Congenital Toxoplasmosis in France and the United States: One Parasite, Two Diverging Approaches. PLoS Negl. Trop. Dis. 2017, 11, e0005222. [CrossRef]

18. Olariu, T.R.; Press, C.; Talucod, J.; Olson, K.; Montoya, J.G. Congenital toxoplasmosis in the United States: Clinical and serologic findings in infants born to mothers treated during pregnancy. Parasite 2019, 26, 13. [CrossRef]

19. Montazeri, M.; Mehrzadi, S.; Sharif, M.; Sarvi, S.; Tanzifi, A.; Aghayan, S.A.; Daryani, A. Drug Resistance in Toxoplasma gondii. Front. Microbiol. 2018, 9, 2587. [CrossRef]

20. Ben-Harari, R.R.; Goodwin, E.; Casoy, J. Adverse Event Profile of Pyrimethamine-Based Therapy in Toxoplasmosis: A Systematic Review. Drugs R D 2017, 17, 523-544. [CrossRef]

21. Sánchez-Sánchez, R.; Ferre, I.; Re, M.; Ramos, J.J.; Regidor-Cerrillo, J.; Pizarro Díaz, M.; González-Huecas, M.; Tabanera, E.; Benavides, J.; Hemphill, A.; et al. Treatment with Bumped Kinase Inhibitor 1294 Is Safe and Leads to Significant Protection against Abortion and Vertical Transmission in Sheep Experimentally Infected with Toxoplasma gondii during Pregnancy. Antimicrob. Agents Chemother. 2019, 63. [CrossRef] 